\title{
ETIKA PESERTA DIDIK DALAM CYBER SYSTEM: SEBUAH TINJAUAN ETIS ALKITABIAH PADA PEMBELAJARAN ERA PENDIDIKAN 4.0
}

\author{
${ }^{1}$ Ayub Budhi Anggoro dan ${ }^{\mathbf{2}}$ Aritya Gusmala Sari \\ ${ }^{1}$ Jurusan Teknik Mesin, Fakultas Teknik, Universitas Negeri Semarang \\ ${ }^{2}$ SMP Negeri 5 Ambarawa \\ Email: anggoroayub@mail.unnes.ac.id
}

\begin{abstract}
ABSTRAK - Revolusi Industri 4.0 (RI 4.0) berdampak pada seluruh bidang termasuk pendidikan dengan munculnya pendidikan 4.0. Pendidikan 4.0 yang bercirikan cyber system berisiko menimbulkan pelanggaran etika. Penelitian ini bertujuan untuk memberikan tinjauan etis alkitabiah terhadap pelanggaran etika dalam pembelajaran cyber system di era revolusi industri 4.0. Penelitian ini menggunakan metode teologi sistematika dengan pendekatan kualitatif yang didasarkan pada penalaran induktif dan paradigma fenomenologi. Hasil penelitian yaitu praktik pelanggaran cyber system merupakan masalah etika yang berisiko untuk terjadi dalam pembelajaran era RI 4.0. Pelanggaran tersebut dapat dilakukan secara sengaja maupun karena faktor ketidaktahuan. Ada 2 hal yang harus dilakukan untuk mencegah pelanggaran itu terjadi dan terbentuknya kehidupan beretika Kristen yang unggul dalam pembelajaran cyber system yaitu pertama, memiliki indentitas yang baru di dalam Yesus Kristus, karena hidup yang utuh dan bermakna itu dimiliki ketika Kristus berdiam dalam diri seseorang. Kedua, praktik pola hidup berintegritas dalam pembelajaran cyber system.
\end{abstract}

Kata Kunci: Cyber System, Etika Alkitabiah, Pembelajaran Era Revolusi Industri 4.0

ABSTRACT - The Industrial Revolution 4.0 (RI 4.0) has an impact on all fields including education with the emergence of education 4.0. Education 4.0 which is characterized by a cyber system is at risk of causing ethical violations. This study aims to provide a biblical ethical review of ethical violations in cyber system learning in the era of the industrial revolution 4.0. This study uses a systematic theological method with a qualitative approach based on inductive reasoning and a phenomenological paradigm. The result of the research shows that cyber system violation practices are ethical issues that are at risk of occurring in the learning era of RI 4.0. These violations can be done intentionally or because of ignorance. There are 2 things that must be done to prevent these violations from occurring and the formation of a Christian ethical life that is superior in cyber system learning, namely first, having a new identity in Jesus Christ, because a full and meaningful life is owned when Christ dwells in a person. Second, practice a lifestyle with integrity in cyber system learning.

Keywords: Cyber System, Biblical Ethics, Learning in the Industrial Revolution Era 4.0 


\section{PENDAHULUAN}

Pendidikan merupakan sektor penting dalam rangka mencerdaskan kehidupan bangsa Indonesia. Hal tersebut tertuang dalam Undang-undang (UU) Nomor 20 tahun 2003 tentang sistem pendidikan nasional pasal 3 menjelaskan bahwa fungsi pendidikan nasional adalah untuk membentuk watak dan peradaban bangsa, serta mengembangkan kemampuan peserta didik. ${ }^{1}$ Lebih lanjut, pendidikan Indonesia berfungsi untuk mengentaskan rakyat Indonesia dari segala penderitaan kebodohan dan ketertinggalan. Pendidikan Indonesia juga berfungsi untuk mengembangkan kemampuan dan membentuk watak serta peradaban bangsa yang bermartabat dalam rangka mencerdaskan kehidupan bangsa. ${ }^{2}$ Hal ini memperlihatkan bahwa penekanan pendidikan Indonesia terletak pada pembangunan sikap, karakter, dan transformasi nilai-nilai filosofis bangsa Indonesia.

Fakta yang terjadi bahwa cita-cita pembangunan sikap, karakter, dan transformasi nilai-nilai filosofis bangsa Indonesia belum menunjukkan hasil yang memuaskan. Hasil survei yang dilakukan oleh Achmadi, dkk tentang persepsi peserta didik terhadap 10 soft skills yang paling dibutuhkan pada abad 21 diperoleh hasil bahwa peserta didik masih merasa membutuhkan pengembangan tanggung jawab sosial, akuntabilitas, dan toleransi

\footnotetext{
${ }^{1}$ Depdiknas, "Undang-Undang Republik Indonesia Nomor 20 Tahun 2003 Tentang Sistem Pendidikan Nasional" (Jakarta, 2003).

2 I Wayan Cong Sujana, "Fungsi Dan Tujuan Pendidikan Indonesia," Adi Widya: Jurnal Pendidikan Dasar 4, no. 1 (July 23, 2019): 29, accessed March 4, 2021,

https://ejournal.ihdn.ac.id/index.php/AW/article/vie w/927.
}

keberagaman. $^{3}$ Hal ini menunjukkan bahwa pendidikan di Indonesia belum memuaskan dalam memenuhi kebutuhan peserta didik dalam mengembangkan sikap, karakter, dan transformasi nilai-nilai filosofis bangsa.

Kurang memuaskannya pembangunan sikap, karakter, dan transformasi nilai-nilai filosofis bangsa Indonesia dipengaruhi oleh berbagai faktor, salah satu di antaranya adalah adanya Revolusi Industri 4.0 (RI 4.0) yang telah memunculkan Pendidikan 4.0. Pendidikan 4.0 adalah pendidikan yang bercirikan pembelajaran cyber system. Pembelajaran cyber system memang memiliki berbagai kelebihan, yaitu tidak terbatas tempat, jarak dan waktu, relatif lebih efisien, menambah keaktifan peserta didik, serta terdapat sumber belajar yang luas. $^{4}$ Namun demikian, selain berbagai kelebihan yang dimiliki, pembelajaran cyber system juga memiliki kekurangan terutama berkaitan dengan kasus etika. Pembelajaran cyber system memungkinkan peserta didik untuk melakukan berbagai kecurangan, di antaranya adalah praktik plagiasi, mengunduh tulisan tanpa izin, membeli karya dari orang lain, menyontek saat ujian, dan lain sebagainya. ${ }^{5}$

Iman Kristen sebagai dasar tindakan orang percaya (pengikut Kristus) perlu memberikan pandangan mengenai

\footnotetext{
${ }^{3}$ Taofan Ali Achmadi et al., "Analisis 10 Tingkat Soft Skills Yang Dibutuhkan Mahasiswa Di Abad 21," Jurnal Teknologi Busana dan Boga 8, no. 2 (2020): 145-151.

${ }^{4}$ Ade Kusmana, "E-Learning Dalam Pembelajaran," Lentera Pendidikan: Jurnal Ilmu Tarbiyah dan Keguruan 14, no. 1 (November 2011): 35-51.

${ }^{5}$ Ahmad Setiadi, "Pelanggaran Etika Pendidikan Pada Sistem Pembelajaran E-Learning," Cakrawala 15 , no. 1 (2015).
} 
kasus pelanggaran etika dalam pembelajaran cyber system di era RI 4.0. Pandangan tersebut diperlukan sebagai upaya agar peserta didik sebagai orang percaya dapat bertindak etis seperti yang diperintahkan oleh Firman Tuhan berkaitan dengan dilema etis tentang pembelajaran cyber system di era RI 4.0. Dengan mengingat bahwa agama dan atau kepercayaan memainkan peranan penting bagi para pengikutnya dalam bersikap dan bertindak. Selain itu, sebagai bagian dari bangsa Indonesia, peserta didik perlu mengambil bagian untuk mewujudkan citacita bangsa dalam pembangunan sikap, karakter, dan transformasi nilai-nilai filosofis bangsa.

Melihat pentingnya peranan agama dan atau kepercayaan bagi pendidikan untuk mewujudkan cita-cita bangsa dalam membangun sikap, karakter, dan adanya transformasi nilai-nilai filosofis bangsa, maka perlu adanya kajian tentang hal tersebut. Untuk itu, penulisan artikel ini bertujuan untuk memberikan pandangan etis alkitabiah mengenai etika peserta didik dalam pembelajaran cyber system di era pendidikan 4.0. Sehingga diharapkan citacita pendidikan Indonesia dapat segera terwujud.

\section{RUMUSAN MASALAH}

Rumusan masalah dalam penelitian ini adalah bagaimana etika peserta didik dalam pembelajaran cyber system era pendidikan 4.0 ditinjau dari sudut pandang etika alkitabiah?

Tujuan dari penelitian ini adalah untuk memberikan pandangan etis alkitabiah mengenai pelanggaran etika dalam pembelajaran cyber system di era pendidikan 4.0.
Manfaat artikel ini yaitu untuk memberikan sebuah tinjauan etis alkitabiah yang dapat digunakan oleh para peserta didik. Tinjauan etis alkitabiah ini dapat dijadikan sebuah pedoman pengambilan keputusan etis dalam pembelajaran cyber system di era pendidikan 4.0.

\section{METODE PENELITIAN}

Penelitian ini menggunakan metode teologi sistematika dengan pendekatan kualitatif yang didasarkan pada penalaran induktif dan paradigma fenomenologi. Metode ini berfokus pada kajian yang telah dirumuskan dan dipegang sebagai dasar iman, pengajaran, dan yang telah diaktualisasikan dalam konteks. ${ }^{6}$

\section{HASIL DAN PEMBAHASAN}

\section{Pelanggaran Etika Dalam Pembelajaran Cyber System}

Perkembangan

teknologi memungkinkan penggandaan data dengan sangat mudah. Pertukaran informasi melalui komputer yang terkoneksi dengan internet menjadi sangat cepat. Oleh sebab itu, pelanggaran etika dalam pembelajaran cyber system dapat dilakukan dengan sangat mudah.

Pelanggaran etika yang umum terjadi dalam pembelajaran cyber system adalah menyalin sebagian atau keseluruhan isi dari karya orang lain tanpa menuliskan sumbernya, menyalin tugas dari sumber yang sama atau dari peserta didik lainnya, mengunduh tulisan tanpa izin, membeli

\footnotetext{
${ }^{6}$ Stevri Indra Lumintang and Danik Astuti Lumintang, Theologia Penelitian Dan Penelitian Theologis, ed. Shendy Carolina Lumintang and Sheren Angelina Lumintang (Jakarta: Geneva Insani Indonesia, 2016), 141-142.
} 
karya dari orang lain yang menjual, menyontek saat evaluasi, mengakui ide, gambar, atau rancangan orang lain, membiarkan karyanya disalin oleh orang lain, dan mengerjakan tugas peserta didik lainnya. $^{7}$

$$
\text { Pelanggaran etika dalam }
$$
pembelajaran cyber system yang telah diuraikan di atas, dapat dikelompokkan dalam beberapa kategori, yaitu plagiasi, pencurian, kecurangan, dan kompromi dengan kejahatan.

\section{Penyebab Pelanggaran Etika Dalam Pembelajaran Cyber System}

Pembelajaran cyber system merupakan pembelajaran yang berpusat pada peserta didik (student centered). Pembelajaran demikian memungkinkan peserta didik untuk memiliki pengalaman belajar dengan melakukan banyak kegiatan secara online. Kegiatan pembelajaran demikian secara psikologis bagi peserta didik dengan harga diri yang tinggi akan lebih kecil kemungkinan untuk melakukan pelanggaran etika, sedangkan bagi peserta didik dengan harga diri yang lebih rendah, pelanggaran etika akan lebih besar kemungkinannya.

Pelanggaran etika juga akan lebih mungkin terjadi bagi peserta didik yang memiliki motivasi yang rendah terhadap penguasaan materi dan cenderung memiliki keinginan yang tinggi untuk mendapatkan nilai yang tinggi. ${ }^{8}$ Motivasi dipengaruhi oleh minat peserta didik sebagai sumber untuk melakukan apa yang

\footnotetext{
${ }^{7}$ Setiadi, "Pelanggaran Etika Pendidikan Pada Sistem Pembelajaran E-Learning."

${ }^{8}$ Mike Hart and Tim Friesner, "Plagiarism and Poor Academic Practice-A Threat to the Extension of eLearning in Higher Education," Electronic Journal on E-learning 2, no. 1 (2004): 89-96.
}

ingin dilakukan. Minat peserta didik untuk melakukan pelanggaran etika dipengaruhi oleh norma subjektif, persepsi kontrol perilaku, dan kewajiban moral.

$\begin{array}{rrr} & \text { Faktor lain yang mendorong } \\ \text { peserta didik untuk melakukan }\end{array}$ pelanggaran etika adalah kurangnya komitmen untuk belajar mandiri, tuntutan dari orang-orang terdekat untuk pencapaian hasil yang terbaik, kurangnya manajemen waktu yang efektif, rendahnya kemampuan dasar peserta didik, website yang seakan-akan adalah milik umum yang semua isinya bebas untuk digunakan, dan anggapan bahwa meniru hasil karya orang lain bukan merupakan tindakan ilegal. ${ }^{9}$

\section{Etika Kristen Untuk Mencegah Pelanggaran Etika Dalam Pembelajaran Cyber System}

\section{Pengertian Etika Kristen}

Etika merupakan refleksi filosofis atas nilai dan moral yang dipegang, dilakukan dengan tekun dalam hidup, dan menjadi dasar dalam bertingkah laku dan bertindak. ${ }^{10}$ Etika berasal dari dalam diri manusia yang dipengaruhi oleh nilai-nilai yang dipegang dan diwujud-nyatakan dalam tindakan. Nilai-nilai moral yang keliru akan memicu pengambilan keputusan etis yang keliru, dan akhirnya akan membuahkan tindakan etis yang keliru pula.

Etika Kristen merupakan etika yang berkenaan dengan ajaran tentang yang baik serta kurang baik dalam benak, perkataan, serta perbuatan manusia bersumber pada Alkitab. Uraian tentang Etika Kristen

\footnotetext{
${ }^{9}$ Setiadi, "Pelanggaran Etika Pendidikan Pada Sistem Pembelajaran E-Learning."

${ }^{10}$ Ibid.
} 
hendak membantu orang-orang menjadi yakin untuk berpikir dengan lebih cerah tentang kehendak Allah supaya mereka dapat meningkatkan hidupnya serta kehidupan warga yang lebih baik dan cocok dengan kehendak Allah. ${ }^{11}$

\section{Fungsi Etika Kristen}

Lebih jauh etika Kristen berfungsi membimbing, menuntun dan memberi petunjuk praktis kepada semua orang Kristen baik individu maupun kelompok dalam membuat keputusan secara benar, tepat dan bertanggungjawab di tengah situasi dan persoalan konkret yang dihadapinya. Kompleksitas persoalan menuntut tanggapan dan orang percaya harus mengatur tingkah lakunya berdasarkan norma-norma yang diatur dalam Alkitab.

\section{Sumber Etika Kristen}

Alkitab merupakan sumber primer untuk mengerti kehendak Allah. Etika Kristen yang tepat harus selalu didasarkan kepada kehendak Allah melalui kebenaran Alkitab. Surat Paulus khususnya 2 Timotius 3: 15-17 menjelaskan bahwa Alkitab adalah Firman Allah yang berotoritas, tidak salah dan keliru karena diilhamkan oleh Allah. Alkitab berguna untuk mengajar, menyatakan kesalahan, memperbaiki kelakuan, dan mendidik orang dalam kebenaran. Firman Allah memiliki kuasa transformatif terhadap kehidupan orang percaya sehingga lebih berkenan kepada Allah. Firman Allah juga akan menjadikan semua orang percaya

\footnotetext{
${ }^{11}$ Malcolm Brownlee, Pengambilan Keputusan Etis Dan Faktor-Faktor Yang Ada Di Dalamnya, 6th ed. (Jakarta, Indonesia: BPK Gunung Mulia, 1991).
}

mampu untuk melakukan pekerjaan baik yang berkenan kepada Allah.

\section{Asas Etika Kristen}

Alkitab menegaskan minimal tujuh
asas kebenaran yang melandasi pengambilan keputusan etis teologis. ${ }^{12}$ Asas pertama, kasih. Kasih berarti takuti, taati, dan ibadahi. Panggilan setiap orang Kristen yaitu adanya sikap hormat kepada Allah dan mewujudkannya dengan hidup. Wujud praktis yaitu menerapkan Firman Allah dalam seluruh aspek kehidupannya sebagai ibadah yang menyenangkan hati Allah (Roma 12: 1).

Kedua, Alkitab adalah firman Allah yang berotoritas dalam seluruh aspek kehidupan. Firman Allah harus dibaca, direnungkan, dan dijadikan acuan dalam pertimbangan dan keputusan etis. Ketiga, Kristosentris. Ajaran dan kehidupan Yesus Kristus harus menjadi teladan dalam pengambilan keputusan etis. Keempat, hidup normal atau taat di dunia yang berdosa. Dunia yang berdosa tidak boleh menjadi alasan agar orang Kristen ikut berdosa. Sebaliknya tetap bertekad hidup taat sekalipun digodai untuk berbuat dosa Kelima, keintiman relasi dengan Allah akan membuat kualitas pengambilan keputusan etis yang lebih berkenan kepada Allah. Upaya menjaga dan meningkatkan keintiman melalui disiplin rohani setiap hari, melalui doa, membaca dan merenungkan Firman Allah, beribadah minggu dan mohon pimpinan Roh Kudus. Keenam, orang percaya dituntut Allah untuk hidup sempurna sebagaimana

\footnotetext{
12 Timotius Haryono et al., Pendidikan Agama Kristen (Surakarta: Lembaga Pengembangan dan Penjaminan Mutu Pendidikan (LPPMP) Universitas Sebelas Maret, 2016), 39-53.
} 
kehendak Allah. Allah menolong manusia untuk hidup sempurna dengan memberikan Firman-Nya dan pertolongan Roh Kudus sehingga manusia dapat hidup sempurna. Ketujuh, kebenaran Firman Allah bersifat universal sehingga dalam situasi dan kondisi atau konteks di mana pun orang percaya harus hidup sesuai seluruh kehendak Allah. Bahkan memberlakukannya di mana pun dan kapan pun. Nilai-nilai etis alkitabiah bersifat normatif teologis bagi pribadi maupun kolektif di seluruh dunia.

\section{Etika PL dan PB}

Pedoman etis teologis untuk orang percaya dinyatakan baik dalam Perjanjian Lama (PL) ataupun Perjanjian Baru (PB). Pedoman etik yang terutama dalam ada dalam kitab Keluaran 20: 1- 17 yang dikenal dengan Dasa Titah. Pertama, jangan ada padamu allah lain di hadapan$\mathrm{Ku}$. Kedua, jangan membuat bagimu patung yang menyamai apa pun juga. Ketiga, jangan menyebut nama TUHAN, Allahmu, dengan sembarangan. Keempat, Ingatlah serta kuduskanlah hari Sabat. Kelima, hormatilah ayahmu serta ibumu. Keenam, jangan melakukan pembunuhan. Ketujuh, jangan berbuat zinah. Kedelapan, jangan mencuri. Kesembilan, jangan mengucapkan saksi dusta tentang sesamamu. Kesepuluh, jangan mengingini kepunyaan sesamamu. Selain dari Taurat, pedoman etis juga bisa ditemui dalam kitab-kitab sejarah, syair, serta nabi besar dan nabi kecil. Semakin orang percaya tekun mendalami seluruh bagian Firman Tuhan di PL maka ia akan diperkaya dalam pemahaman dan akan berdampak pada kualitas pengambilan keputusan etisnya.
PB juga menyediakan pedoman etis teologis bagi orang percaya. Tuhan Yesus mengajarkan dalam Matius pasal 5-7 bahwa Ia akan memperlengkapi dengan pemahaman tentang etika kerajaan Allah bagi semua orang percaya sebagai warga kerajaan Allah. Tuhan Yesus juga meringkaskan hukum kasih-Nya dalam Injil Matius 22: 3-40 demikian:

"Kasihilah Tuhan, Allahmu,
dengan segenap hatimu dan
dengan segenap jiwamu dan
dengan segenap akal budimu.
Itulah hukum yang terutama dan
yang pertama. Dan hukum yang
kedua, yang sama dengan itu,
ialah: Kasihilah sesamamu
manusia seperti dirimu sendiri.
Pada kedua hukum
inilah tergantung seluruh hukum
Taurat dan kitab para nabi."

Jadi pengambilan keputusan etis haruslah berdasarkan motif kasih dan bersifat totalitas dan utuh. Prinsip-prinsip etis teologis juga diajarkan oleh para rasul sebagaimana ditemukan dalam kitab Kisah Para Rasul, surat-surat rasuli dan wahyu. Artinya dengan mempelajari PL dan PB orang percaya dapat mengenal kehendak Allah secara mendalam dan menyeluruh dan kemudian diterapkan secara konsisten dalam menyikapi persoalan etis sehingga hidupnya berkenan kepada Allah.

\section{Pengambilan Keputusan Etis Alkitabiah}

Keputusan etis tidak cuma dipengaruhi oleh norma-norma yang dipertimbangkan serta penafsiran kita tentang keadaan, namun juga oleh 
keyakinan kita, tabiat serta area sosial. ${ }^{13}$ Kita cuma bisa menguasai pengambilan keputusan etis bila kita memperhitungkan hal-hal yang tidak dipertimbangkan dikala pengambilan keputusan. Dalam mengambil keputusan etis perlu memahami secara menyeluruh, bahkan sampai pada hal-hal yang tidak dipikirkan. Pengambilan keputusan etis membutuhkan kejernihan pikiran untuk benar-benar dapat mempertimbangkan semua faktor secara menyeluruh.

Secara praktis pada saat seorang atau sekelompok orang Kristen menghadapi masalah, maka pertanyaan yang seharusnya muncul adalah apakah yang seharusnya saya atau kami lakukan sebagai orang percaya? Bertolak dari hal ini maka sebagai orang percaya, langkah awal harus merujuk kepada Firman Allah yang berbicara tentang isu tersebut. Selanjutnya memohon bimbingan Roh Kudus dan dengar-dengaran pada hati nurani agar dengan kesadaran diri melakukan pertimbangan etis teologis dan terhindar dari pertimbangan etis yang tidak alkitabiah. Dan kemudian membuat keputusan etis serta diikuti tindakan etis alkitabiah. ${ }^{14}$

Oleh karena corak berpikir etis teologis bersifat deontologis (etika kewajiban) maka panggilan untut taat menerapkan Firman Allah itulah keputusan yang berkenan kepada Allah dan mendatangkan damai sejahtera serta berkat bagi orang percaya. Hal ini akan berlaku

\footnotetext{
${ }^{13}$ Brownlee, Pengambilan Keputusan Etis Dan Faktor-Faktor Yang Ada Di Dalamnya.

${ }^{14}$ Samuel Kusuma, Etika Dan Perilaku Kristiani (Balikpapan: Institut Kristen Borneo, 2017), 110 122.
}

baik terhadap persoalan etis yang sederhana maupun kompleks.

\section{Penilaian Etis Terhadap Pelanggaran} dalam Pembelajaran Cyber System

Dunia akademis dengan aktivitas pembelajarannya juga merupakan area penerapan etika Kristen. Sehingga, setiap peserta didik Kristen yang sungguhsungguh harus menyadari aneka tantangan iman dalam pembelajaran cyber system.

Mencermati praktik plagiasi, pencurian, kecurangan, dan kompromi dengan kejahatan dan pembelajaran cyber system, sejatinya merupakan pelanggaran hukum Allah "Jangan mencuri", "Jangan mengucapkan saksi dusta", "Jangan mengingini milik sesamamu”, Allah mengakui kepemilikan seseorang atau kepemilikan sekelompok orang dan Allah menghendaki orang percaya menyadarinya. Allah menghendaki kejujuran dan sikap menahan diri terhadap keserakahan dan serta mau bersyukur terhadap apa yang dimilikinya. Pelanggaran etis dalam pembelajaran cyber system juga menunjukkan orang Kristen tidak mengasihi Allah dan sesamanya.

Penyebab pelanggaran etika dalam pembelajaran cyber system di antaranya adalah faktor minat atau motivasi, komitmen, ketidaktahuan, dan tuntutan untuk menjadi terbaik. Melihat hal tersebut, minat atau motivasi, komitmen, dan ketidaktahuan merupakan faktor pengaruh internal, sedangkan tuntutan menjadi terbaik merupakan faktor pengaruh eksternal.

Faktor internal dan eksternal manusia dipengaruhi iman seseorang. Iman merupakan pengikutsertaan dalam 
pekerjaan Allah. ${ }^{15}$ Kolose 3: 23 mengatakan bahwa, "Apapun juga yang kamu perbuat, perbuatlah dengan segenap hatimu seperti untuk Tuhan dan bukan untuk manusia". Jadi seharusnya dalam melakukan setiap aktivitas seorang percaya melakukannya seperti untuk Tuhan. Hal ini memiliki arti yang dalam, yang berarti bahwa dalam segala hal yang dikerjakan selalu mengakui kehadiran Allah dan melibatkan Allah dalam pekerjaan tersebut. Persoalannya adalah apabila seseorang belum mengenal Allah di dalam Yesus Kristus akan sulit mewujudkan pengikutsertaan Allah dalam hidup termasuk dalam pembelajaran.

Pengaruh lainnya terkait dengan tabiat ataupun kepribadian manusia. Tabiat ialah lapisan batin seorang yang memberikan arah serta kedisiplinan kepada kemauan, kesukaan, serta perbuatan seorang. Susunan ini dibangun oleh interaksi antara diri orang dengan area sosialnya, serta Allah. Ikatan manusia dengan Allah mengubah hati serta karakter seorang tersebut. Kitab 2 Korintus 5: 17 berkata jika manusia merupakan ciptaan yang baru di dalam Kristus. Pesan 1 Petrus 1: 23 berkata kalau, di dalam Kristus, manusia sudah dilahirkan kembali dari benih yang tidak fana. Dengan demikian, manusia di dalam Kristus sudah dikuburkan serta dibangkitkan bersamasama dengan Kristus (Roma 6: 4). Kehidupan manusia di dalam Kristus menjadikan manusia sebagai ciptaan baru dengan tabiat yang diperbaharui, sehingga seharusnya dengan tabiat yang baru maka perbuatan-perbuatan manusia menjadi lebih baik. Permasalahannya adalah

\footnotetext{
${ }^{15}$ Brownlee, Pengambilan Keputusan Etis Dan Faktor-Faktor Yang Ada Di Dalamnya.
}

bagaimana seseorang dapat mengalami pembaruan karakter dan hidup sebagaimana mestinya. Itulah sebabnya diperlukan penyelesaian yang utuh dalam diri insan pembelajar agar dapat hidup beretika yang unggul, sebagaimana dipaparkan berikut ini.

\section{Hidup Beretika Dalam Pembelajaran Cyber System \\ Mencermati modus pelanggaran} dalam pembelajaran cyber system dan faktor penyebabnya, maka hidup beretika dalam pembelajaran pada hakikatnya adalah kejujuran. ${ }^{16}$ Hidup beretika dalam pembelajaran cyber system bagi insan akademis Kristen harus berpijak pada dua aspek yang tidak terpisahkan, yaitu pertama, identitas diri atau gambar diri yang alkitabiah dan kedua, praktik hidup berintegritas. Artinya hidup yang sesuai dengan jati dirinya "Siapakah saya menentukan apa yang saya perbuat".

Pertama, identitas diri atau gambar diri yang alkitabiah. Identitas diri adalah gambaran atau perasaan yang didapatkan, dimiliki, dan dikembangkan tentang dirinya. ${ }^{17}$ Seorang mempunyai gambar diri yang alkitabiah diawali dengan pengenalan kepada Yesus Kristus selaku Tuhan serta Juru selamatnya secara individu. Gambar diri yang utuh serta bermakna itu dipunyai

\footnotetext{
${ }^{16}$ Hery Harjanto, "Hubungan Pendidikan Agama Kristen Di UNS Dengan Etika Akademis Mahasiswa," Jurnal Penelitian Gamaliel 1, no. 2 (2013): 83-89, accessed March 18, 2021, https://drive.google.com/file/d/1pdrde94kNGQsC6 7tWo11WCwj1Q1F_gKd/view.

${ }^{17}$ Soleman Kawangmani and Irawan Budi Lukmono, "Efektivitas Pembelajaran Agama Kristen Melalui Mata Kuliah Pendidikan Agama Kristen Di Perguruan Tinggi Terhadap Pemahaman Mahasiswa Kristen Tentang Gambar Diri," Jurnal Gamaliel : Teologi Praktika 2, no. 1 (March 30, 2020): 3-10.
} 
kala Kristus berdiam di dalam diri seorang. ${ }^{18}$ Dengan beriman kepada Kristus manusia berdoa dilahirkan baru. Untuk mengalami kelahiran baru diawali dengan kesadaran diri sebagai orang berdosa dan upah dosa membawanya kepada maut (Roma 3: 23, 6: 23). Usahanya dengan cara untuk menyelamatkan diri dari maut itu sia-sia (Efesus 2: 8-9). Yesuslah satusatunya Tuhan dan Juru Selamat yang telah menanggung dosanya di kayu salib, mati, dikuburkan, dan bangkit serta telah menyediakan pengampunan dosa dan kehidupan kekal (1 Petrus 2: 24). Lalu ada keterbukaan hati mau beriman dan menerima Yesus sebagai Tuhan dan Juru Selamatnya (Yohanes 1: 12), maka saat itulah Roh Kudus akan melahir-barukan orang tersebut (Yohanes 3: 3-7). ${ }^{19}$

Kelahiran membawa identitas baru yaitu bukan lagi manusia berdosa, tetapi anak-anak Allah. Seseorang yang telah dilahirkan baru akan memperoleh sebutan yang baru. Alkitab menyatakan begitu banyak sebutan baru kepada orang percaya, antara lain: garam dunia (Matius 5: 13), terang dunia (Matius 5: 14) anak Allah (Yohanes 1: 12), ranting dari pokok anggur yang benar (Yohanes 15: 1,5), sahabat Kristus (Yohanes 15: 15) dipilih dan diperintahkan oleh Kristus untuk berbuah (Yohanes 15: 16), hamba kebenaran (Roma 6: 18), hamba Allah

\footnotetext{
18 Yuliati Yuliati and Stanley Santoso, "Pengaruh Pendidikan Agama Kristen Dalam Peningkatkan Pemahaman Mahasiswa Kristen Tentang Kristologi Alkitabiah," Jurnal Gamaliel : Teologi Praktika 2, no. 1 (March 30, 2020): 11-19, accessed March 18, 2021, https://jpp.go.id/humaniora/.

${ }^{19}$ T. Haryono and Kezia Yemima, "Pemahaman Soteriologi Alkitabiah Mahasiswa Kristen UNS Surakarta," PASCA: Jurnal Teologi dan Pendidikan Agama Kristen 16, no. 2 (November 5, 2020): 152 163.
}

(Roma 6: 22), anak Allah; Saya adalah anak Allah secara rohani (Roma 8: 14-15; Galatia 3: 26, 4: 6), bersama Kristus sebagai ahli waris (Roma 8: 17, Galatia 4: 6-7), bait Allah; di dalam saya ada Roh dan kehidupan Allah (I Korintus 3: 16, 6: 19), menjadi satu roh dengan Tuhan Yesus karena telah dipersatukan dengan Dia (1 Korintus 6: 17), adalah anggota tubuh Kristus (1 Korintus 12: 27; Efesus 5: 30), ciptaan yang baru (2 Korintus 5: 17), dipercaya untuk melaksanakan pelayanan pendamaian sebagai seorang yang telah diperdamaikan dengan Allah (2 Korintus 5: 18-19), anak Allah dan satu di dalam Kristus (Galatia 3: 26, 28), orang kudus (Efesus 1: 1; 2 Korintus 1: 2, Filipi 1: 1, Kolose 1: 2), buatan Allah yang diciptakan di dalam Kristus untuk melaksanakan pekerjaan-Nya (Efesus 2: 10), warga surga bersama dengan anggota keluarga Allah yang lain (Efesus 2: 19), tawanan Kristus (Efesus 3: 1, 4: 1), di dalam kebenaran dan kekudusan (Efesus 4: 24), telah mendapatkan tempat di surga sebagai warga negara kerajaan surga (Filipi 3:20, Efesus 2: 6), tersembunyi bersama Kristus di dalam Allah (Kolose 3: 4), anak terang dan bukan anak gelap (1 Tesalonika 5: 5), pernyataan kehidupan Kristus sebab Kristus adalah kehidupan saya (Kolose 3: 4), pilihan Allah, kudus dan sangat dikasihi (Kolose 3: 12; 1 Tesalonika 1: 4), mendapat bagian di dalam panggilan surgawi (Ibrani 3: 1), beroleh bagian di dalam Kristus dan kehidupan-Nya (Ibrani 3: 14), salah satu batu hidup Allah, yang di dalam Kristus sedang dipergunakan untuk pembangunan rumah rohani (1 Petrus 2: 5), musuh iblis (1 Petrus 5: 8), umat Allah yang terpilih, imamat yang rajani, bangsa yang kudus, umat kepunyaan Allah sendiri 
(1 Petrus 2: 9-10), pendatang dan perantau di dalam dunia, dan dunia adalah tempat tinggal sementara (1 Petrus 2: 11) anak Allah dan akan menjadi serupa dengan Kristus pada waktu Ia datang kembali (1 Yohanes 3: 1-2), dilahirkan kembali dari Allah, si jahat tidak dapat menyentuh (1 Yohanes 5:18), oleh kasih karunia Allah, saya adalah sebagaimana saya ada sekarang (1 Korintus 15: 10).

Kedua, praktik pola hidup berintegritas. Prinsip hidup berintegritas secara sederhana dirumuskan sebagaimana contoh berikut ini: "Saya mahasiswa Kristen adalah anak-anak Allah, ciptaan baru, orang kudus, anak-anak terang, murid Kristus, karena itu saya tidak akan melakukan plagiasi, pencurian hak kekayaan intelektual orang lain, kecurangan, dan kompromi dengan kejahatan dalam pembelajaran cyber system karena perbuatan ini tidak sesuai dengan identitas diri saya sebagai mahasiswa Kristen." Perwujudan praktis berkelanjutan yaitu tidak mau membeli karya orang lain, bergairah dalam merumuskan ide dan gagasan kreatif dalam pembelajaran, tekun mengikuti pembelajaran luring dan atau daring sebagai bukti seorang murid Kristus, memiliki motivasi, attitude dan semangat berprestasi yang tinggi dan selalu mengejar yang terbaik sebagai bukti bahwa mengasihi Allah dengan segenap akal budi dan totalitas hidup.

Untuk meneguhkan dan menambah kokoh jati diri agar hidup berintegritas maka perlu menumbuhkembangkan spiritualitas yang unggul. Sebab pertobatan dan kelahiran baru adalah awal kehidupan rohani yang berorientasi kepada pembangunan tabiat serta karakter ilahi untuk mencapai keserupaan dengan Kristus melalui pemuridan (Matius 28: 18-20; Efesus 2: 11-16). ${ }^{20}$ Proses pertumbuhan dan pendewasaan rohani ini dilakukan untuk memperteguh hidup beriman di dalam Kristus, pembentukan pola hidup ilahi, termasuk di dalamnya pemahaman tentang arti etika, asas dan pedoman etika Kerajaan Allah, serta panggilan hidup sebagai garam dan terang dalam dunia yang gelap dan berdosa (Matius 5: 13-17). Hal-hal praktis dimulai dengan meningkatkan kualitas doa, pembelajaran Firman Allah, dan hidup ibadah. Pendidikan Agama Kristen di kampus juga menjadi bagian integral dalam pembentukan spiritualitas insan akademis. Dalam kerangka pembelajaran maupun terkait dengan pengembangan relasi dengan sesama insan akademis dan lingkungannya secara benar, tanpa kompromi dengan dunia, serta menjadi saksi Kristus yang menuntun orang lain kepada praktik hidup berintegritas.

\section{KESIMPULAN}

Praktik pelanggaran cyber system merupakan masalah etika yang berisiko untuk terjadi dalam pembelajaran era Pendidikan 4.0. Pelanggaran tersebut dapat dilakukan secara sengaja maupun karena faktor ketidaktahuan. Ada 2 hal yang harus dilakukan untuk mencegah pelanggaran itu terjadi dan terbentuknya kehidupan beretika Kristen yang unggul dalam pembekajaran cyber system yaitu pertama, memiliki identitas yang baru di dalam Yesus Kristus, karena hidup yang utuh dan

\footnotetext{
${ }^{20}$ Efi Nurwindayani, "Hubungan Pemuridan Kontekstual Di Fakultas Keguruan Dan Ilmu Pendidikan UNS Dengan Spiritualitas Mahasiswa," Jurnal Penelitian Gamaliel 1, no. 2 (2013): 83-90.
} 
Jurnal Gamaliel : Teologi Praktika

Vol 3, No 1, Maret 2021

bermakna dimiliki ketika Kristus berdiam dalam diri seseorang. Kedua, praktik pola hidup berintegritas dalam pembelajaran cyber system. 


\section{REFERENSI}

Achmadi, Taofan Ali, Ayub Budhi Anggoro, Lia Sari, and Devi Anggriyani. "Analisis 10 Tingkat Soft Skills Yang Dibutuhkan Mahasiswa Di Abad 21." Jurnal Teknologi Busana dan Boga 8, no. 2 (2020): 145-151.

Brownlee, Malcolm. Pengambilan Keputusan Etis Dan Faktor-Faktor Yang Ada Di Dalamnya. 6th ed. Jakarta, Indonesia: BPK Gunung Mulia, 1991.

Depdiknas. "Undang-Undang Republik

Indonesia Nomor 20 Tahun 2003

Tentang Sistem Pendidikan

Nasional." Jakarta, 2003.

Harjanto, Hery. "Hubungan Pendidikan

Agama Kristen Di UNS Dengan Etika

Akademis Mahasiswa." Jurnal

Penelitian Gamaliel 1, no. 2 (2013).

Accessed March 18, 2021.

https://drive.google.com/file/d/1pdrde 94kNGQsC67tWo11WCwj1Q1F_gK $\mathrm{d} /$ view.

Hart, Mike, and Tim Friesner. "Plagiarism and Poor Academic Practice-A Threat to the Extension of e-Learning in Higher Education." Electronic Journal on E-learning 2, no. 1 (2004): 89-96.

Haryono, Timotius, Trifena Yuliati, Soleman Kawangmani, Hery Harjanto, and Efi Nurwindayani. Pendidikan Agama Kristen. Surakarta: Lembaga Pengembangan dan Penjaminan Mutu Pendidikan (LPPMP) Universitas Sebelas Maret, 2016.

Kawangmani, Soleman, and Irawan Budi Lukmono. "Efektivitas Pembelajaran Agama Kristen Melalui Mata Kuliah
Pendidikan Agama Kristen Di

Perguruan Tinggi Terhadap

Pemahaman Mahasiswa Kristen

Tentang Gambar Diri." Jurnal

Gamaliel : Teologi Praktika 2, no. 1

(March 30, 2020).

Kusmana, Ade. "E-Learning Dalam

Pembelajaran." Lentera Pendidikan:

Jurnal Ilmu Tarbiyah dan Keguruan

14, no. 1 (November 2011): 35-51.

Kusuma, Samuel. Etika Dan Perilaku

Kristiani. Balikpapan: Institut Kristen Borneo, 2017.

Lumintang, Stevri Indra, and Danik Astuti

Lumintang. Theologia Penelitian Dan

Penelitian Theologis. Edited by

Shendy Carolina Lumintang and

Sheren Angelina Lumintang. Jakarta:

Geneva Insani Indonesia, 2016.

Nurwindayani, Efi. "Hubungan Pemuridan

Kontekstual Di Fakultas Keguruan

Dan Ilmu Pendidikan UNS Dengan

Spiritualitas Mahasiswa." Jurnal

Penelitian Gamaliel 1, no. 2 (2013):

83-90.

Setiadi, Ahmad. "Pelanggaran Etika

Pendidikan Pada Sistem Pembelajaran

E-Learning." Cakrawala 15, no. 1 (2015).

Sujana, I Wayan Cong. "Fungsi Dan

Tujuan Pendidikan Indonesia." Adi

Widya: Jurnal Pendidikan Dasar 4, no. 1 (July 23, 2019): 29. Accessed March 4, 2021.

https://ejournal.ihdn.ac.id/index.php/

AW/article/view/927.

T. Haryono, and Kezia Yemima.

"Pemahaman Soteriologi Alkitabiah

Mahasiswa Kristen UNS Surakarta."

PASCA: Jurnal Teologi dan

Pendidikan Agama Kristen 16, no. 2

(November 5, 2020): 152-163. 
Yuliati, Yuliati, and Stanley Santoso.

"Pengaruh Pendidikan Agama Kristen

Dalam Peningkatkan Pemahaman

Mahasiswa Kristen Tentang

Kristologi Alkitabiah.” Jurnal

Gamaliel : Teologi Praktika 2, no. 1

(March 30, 2020). Accessed March

18, 2021. https://jpp.go.id/humaniora/. 